\title{
Toxicity of organic and inorganic nanoparticles to four species of white-rot fungi
}

\author{
T.P.S. Galindo a,b,*, R. Pereira ${ }^{\text {a,e }}$, A.C. Freitas ${ }^{a, c, d}$, T.A.P. Santos-Rocha ${ }^{a, c, d}$, M.G. Rasteiro ${ }^{f}$, F. Antunes ${ }^{\text {, }}$, \\ D. Rodrigues ${ }^{\text {a,c,d }}$, A.M.V.M. Soares ${ }^{\text {a,b }}$, F. Gonçalves ${ }^{\text {a,b }}$, A.C. Duarte ${ }^{\text {a,c }}$, I. Lopes ${ }^{\text {a,b }}$ \\ a CESAM, Universidade de Aveiro, Campus Universitário de Santiago, 3810-193 Aveiro, Portugal \\ ${ }^{\mathrm{b}}$ Departamento de Biologia, Universidade de Aveiro, Campus Universitário de Santiago, 3810-193 Aveiro, Portugal \\ c Departamento de Química, Universidade de Aveiro, Campus Universitário de Santiago, 3810-193 Aveiro, Portugal \\ d ISEIT, Instituto Piaget Viseu, Estrada do Alto do Gaio, Lordosa, 3515-776 Viseu, Portugal \\ e Departamento de Biologia, Faculdade de Ciências, Universidade do Porto, Rua do Campo Alegre 4169-007 Porto, Portugal \\ ${ }^{\mathrm{f}}$ Department of Chemical Engineering, University of Coimbra, 3030-290 Coimbra, Portugal
}

\section{H I G H L I G H T S}

- Nanoparticles (NP) tend to aggregate when in aqueous suspensions.

- Chemical composition revealed to be very important in the ecotoxicity of NP.

- Observed effects suggested diversified modes of action of different NP.

- White-rot fungi species exhibit great differences in their sensitivity to NP.

\section{A R T I C L E I N F O}

\section{Article history}

Received 2 November 2012

Received in revised form 7 March 2013

Accepted 6 April 2013

Available online 8 May 2013

\section{Keywords:}

Basidiomycota

FTIR

Growth inhibition

Light scattering

Nanomaterials

\begin{abstract}
A B S T R A C T
The rapid development of nanoparticles (NP) for industrial applications and large-volume manufacturing, with its subsequent release into the environment, raised the need to understand and characterize the potential effects of NP to biota. Accordingly, this work aimed to assess sublethal effects of five NP to the white-rot fungi species Trametes versicolor, Lentinus sajor caju, Pleurotus ostreatus, and Phanerochaete chrysosporium. Each species was exposed to serial dilutions of the following NP: organic-vesicles of SDS/DDAB and of Mo/NaO; gold-NP, quantum dot $\mathrm{CdSe} / \mathrm{ZnS}$, and $\mathrm{Fe} / \mathrm{Co}$. Fungi growth rate was monitored every day, and at the end of assay the mycelium from each replicate was collected to evaluate possible changes in its chemical composition. For all NP-suspensions the following parameters were characterized: hydrodynamic diameter, surface charge, aggregation index, zeta potential, and conductivity. All tested NP tended to aggregate when suspended in aqueous media. The obtained results showed that gold-NP, CdSe/ZnS, Mo/NaO, and SDS/DDAB significantly inhibited the growth of fungi with effects on the mycelium chemical composition. Among the tested NP, gold-NP and CdSe/ZnS were the ones exerting a higher effect on the four fungi. Finally to our knowledge, this is the first study reporting that different types of NP induce changes in the chemical composition of fungi mycelium.
\end{abstract}

(c) 2013 Elsevier B.V. All rights reserved.

\section{Introduction}

Within the last decade nanotechnology exhibited a massive growth, producing a large number of new nanoparticles (NP), already being used in a wide variety of industry sectors (medicine, cosmetics, electronics; Kahru and Dubourguier, 2010). Such NP use needs a parallelimproved understanding of their potential impacts on environment, as their new features (e.g. electrical conductivity, increased reactivity) may influence their toxicity comparatively with corresponding bulk

\footnotetext{
* Corresponding author at: Centro de Estudos do Ambiente e do Mar, Departamento de Biologia da Universidade de Aveiro, Campus de Santiago, P-3810-193 Aveiro, Portugal. Tel.: + 351234 370779; fax: + 351234372587.

E-mail address: pgalindo@ua.pt (T.P.S. Galindo).
}

material (Bar-Ilan et al., 2009). Accordingly, within the last few years, studies on the ecotoxicity of several NP greatly increased, accounting for their potential effects in biota: bacteria (Pereira et al., 2011; Lopes et al., 2012), fungi (Navarro et al., 2008), algae and plants (Navarro et al., 2008), crustacean (Heinlaan et al., 2011), fish (Bar-Ilan et al., 2009), amphibians (Mouchet et al., 2011; Salvaterra et al., 2012), among others; and at different levels of biological organization (e.g. mortality, oxidative stress, DNA damage; Landsiedel et al., 2009; Scown et al., 2010; Manzo et al., 2011). Though such high amount of knowledge has been generated, it can still be considered limited, since NP consist in an infinite number of chemical composition, size/shape, surface coatings, which provide them specific properties that influence their ecotoxicity. Also, imbalance knowledge still exists regarding NP effects to aquatic and soil organisms, the former being more extensively studied than the latter ones (Bernhardt et al. 
2010). Thus, given the considerable uncertainty existing about the safety of many NP, it is essential to generate more information to better understand and minimize environmental risks. Namely, few data still exists regarding NP effects in the terrestrial compartment. Solid phase of soils provides a large and reactive sink for NP, which may easily attain surface soils by disposal of wastewater treatment plant sewage sludge as well through intentional applications for remediation purposes (Klaine et al., 2008; Tourinho et al., 2012; Wiesner et al., 2006). Once in this matrix NP can be uptake by biota inducing harmful effects (Dinesh et al., 2012). Within soil biota, microorganisms play an important role in the proper health, production and functions of most ecosystems. Specifically, white-rot fungi play important roles in carbon and nitrogen cycling, decomposing organic matter and biotic interactions (Bing-Ru et al., 2006). Thus, if NP negatively affects the growth of this group of organisms, repercussions in the structure of soil and function of the respective ecosystem are expected to occur.

According, the present study aimed at assessing the effects of aqueous media contaminated with three inorganic (gold nanorods; $\mathrm{QD}$ - quantum dots of $\mathrm{CdSe} / \mathrm{ZnS}$, and $\mathrm{Fe} / \mathrm{Co}$ ) and two organic (vesicles of SDS/DDAB and of Mo/NaO) NP in four species of white-rot fungi. These selected NP are already being used/commercialized in our society. For example, magnetic Fe/Co NP, which are commonly synthesized through diffusion cloud chamber setup within pulsed laser deposition (PLD) equipment (Ong et al., 2008), are largely used in ultrahigh density data storage, biosensors, and biomedicine (Behrens et al., 2006). Regarding QD, they are largely applied in biomedical imaging and electronics industries (Hardman, 2006), being one of the most recent methodologies used to produce it, microwave electromagnetic irradiation (for an overview about a multitude of QD synthesis methods please see Schumacher et al., 2009). Gold nanorods are synthesized using dispersions, such as toluene and water. They can be grown by the so-called seed mediated process in water solutions of a cationic surfactant cetyltrimethylammonium bromide $\left(\mathrm{C}_{16} \mathrm{H}_{33}\right) \mathrm{N}\left(\mathrm{CH}_{3}\right)_{3} \mathrm{Br}$, abbreviated as CTAB. These NP are also used in biomedicine (e.g. biodiagnostic assays; Dreaden et al., 2012). Finally, the organic vesicles of SDS/DDAB and $\mathrm{Mo} / \mathrm{NaO}$ are usually prepared by self assemblage, and can be used in detergents, paints, cosmetics, and have recently been proposed for controlled drug delivery (Antunes et al., 2004; Borné et al., 2003; Ferreira et al., 2006).

\section{Material and methods}

\subsection{Test species}

Four Basidiomycota species were used: Lentinus sajor caju (Fries) Fries (formerly known as Pleurotus sajor caju (Fries) Singer) and Pleurotus ostrearus (Jacquin) P. Kummer were obtained from UNESP (São Paulo State University, Brazil), and Phanerochaete chrysosporium (Burdsall 38388) and Trametes versicolor (Pilát 38412), obtained from BCCMTM/ MUCL Culture Collection (Belgium). All species were cultured at $25{ }^{\circ} \mathrm{C}$ for 3 days (P. chrysosporium) or 8 days (L. sajor caju, P. ostreatus and $T$. versicolor) in Potato Dextrose Agar (PDA, Merck, Darmstadt, Germany) before assays.

\subsection{Tested NP-suspensions}

Three inorganic (Fe/Co, CdSe/ZnS-QD, gold nanorods-NP-Au) and two organic (vesicles of sodium dodecyl sulfate and didodecyldimethylammonium bromide-SDS/DDAB and of monoolein and sodium oleate- $\mathrm{Mo} / \mathrm{NaO}$ ) NP were studied in this work. The $\mathrm{Fe} / \mathrm{Co}$ (particle size: $7 \mathrm{~nm}$ ), CdSe/ZnS (particle size: $3.4 \mathrm{~nm}, 5 \mathrm{mg} / \mathrm{mL}$ toluene), NP-Au (particle size: axial dimension $=10 \mathrm{~nm}$ and long size dimension $=35 \mathrm{~nm}$, absorbance peak: $750 \mathrm{~nm}$ ), SDS/DDAB (particle size: $30 \mathrm{~nm}$; Antunes et al., 2004), and Mo/NaO (particle size: $60 \mathrm{~nm}$; Borné et al., 2003) were supplied by: StremChemicals, Inc. (Cambridge, England), Sigma-Aldrich (St. Luis, MO, USA), Nanopartz ${ }^{\mathrm{TM}}$ (Salt Lake
City, UT, USA), Akzo Nobel Surface ChemistryAB (Stenungsund, Sweden), Sigma-Aldrich, Danisco Ingredients (Braband, Denmark), and Nu-Chek Prep, Inc. (Elysian, MN, USA), respectively. Inorganic NP were ordered as dispersions: Fe/Co (information provided by the manufacturer - $97 \%$ of toluene, $0.3 \%$ of cashew nut shell liquid and $2 \%$ of metallic compound); QD and NP-Au were dispersed in toluene and in Milli-Q® water with ascorbic acid and cetyltrimethylammonium bromide surfactant capping agent, respectively. The stock dispersion of sodium dodecylsulfate/didodecyldimethylammonium bromide (SDS/DDAB) vesicles was prepared as follows: a $55 \mathrm{mM}$ surfactant stock solution (sodium dodecylsulfate + didodecyldimethylammonium bromide) with a mole fraction of sodium dodecylsulfate corresponding to 0.71 ((XSDS) CSDS/(CSDS + CDDAB)) (C refers to concentration in $\mathrm{mol} / \mathrm{L}$, while $\mathrm{X}$ means the mole fraction-dimensionless) was prepared by mixing a sodiumdodecylsulfatemicellar solution and a didodecyldimethylammonium bromide homogenized dispersion. Conditions for preparing the stock suspensions of the two vesicles followed previous reports (Pereira et al., 2011; Lopes et al., 2012). For all NP, the highest tested concentration was prepared by direct dilution of dispersions with sterilized Milli-Q ${ }^{\circledR}$ water, being the subsequent concentrations prepared by diluting the highest one with sterilized Milli-Q® water. Tested concentrations were selected according with data obtained by Pereira et al. (2011) and Nogueira et al. (2012) for these NP: 965, 1157, 1389, 1667 and $2000 \mu \mathrm{L} / \mathrm{L}$ for Fe/Co; 0.5, 1.0, 2.0, 4.0 and $8.0 \mathrm{mg} / \mathrm{L}$ for QD; 15.9, 19.1, 22.9, 27.5 and 33 (last concentration corresponds to $100 \%$ of the NP-Au dispersion) $\mathrm{mg} / \mathrm{L}$ for NP-Au; 3.3, 3.9, 4.7, 5.8 and $6.8 \mathrm{~g} / \mathrm{L}$ for SDS/DDAB; and 9.8, 11.7, 13.9, 16.8 and $20.0 \mathrm{~g} / \mathrm{L}$ for $\mathrm{Mo} / \mathrm{NaO}$.

\subsection{Characterization of NP in suspension}

Hydrodynamic diameter (a measure of NP size), aggregation index, polydispersity index (PDI; measure of particle size distribution width), zeta potential (measure of dispersion stability), and surface charge were characterized at the highest NP-concentrations, by using dynamic light scattering (DLS) and electrophoretical light scattering (ELS) in Zetasizer Nano-ZS (Malvern Instruments Ltd, Worcestershire, UK), at $20{ }^{\circ} \mathrm{C}$ and backward scattering $\left(173^{\circ}\right)$. Inorganic NP were also visualized by emission transmission-electron microscopy (TEM; Philips CM100; Fei Company) (for organic NP this technique could not be used as vesicles collapse when not in aqueous suspension), operating at $80 \mathrm{keV}$, at different magnifications $(60,000 \times$; 64,000×). Samples were prepared by slow evaporation, at room temperature, of one drop of NP-suspension placed on a carbon coated copper grid (70-90 nm thickness, 200 mesh) for field emission TEM.

\subsection{Exposure of fungi to NP-suspensions}

Each fungus was exposed to each NP in Petri dishes (diameter: $80 \mathrm{~mm}$ ) containing $3.9 \%$ of PDA (prepared with Milli-Q ${ }^{\circledR}$ sterilized water) and $500 \mu \mathrm{L}$ of each NP-suspension or Milli-Q ${ }^{\circledR}$ water solely (control) that were directly applied and evenly spread in agar surface. Afterwards, for each fungus, Petri dishes were inoculated with a single circular 7-mm mycelia plug removed from the edge of an actively growing colony and incubated at $28{ }^{\circ} \mathrm{C}$ in the dark. Three replicates were performed for control and NP-concentrations.

During assays, three measurements (minimum, maximum and diagonal diameters; using a ruler-mm) were performed daily to compute an average diameter of the colony. For each fungus, the assay was considered ended when control Petri dishes were totally covered by the respective mycelium. At the end of assays, the mycelium of each fungus was collected by careful scraping from the three replicates in sterile tubes, frozen at $-80^{\circ} \mathrm{C}$, lyophilized and stored in a dry controlled environment until Fourier Transform Spectroscopy (FTIR) analysis. 


\subsection{FTIR analysis}

FTIR spectroscopy was used to analyze changes in chemical composition of the fungi mycelium (Movasaghi et al., 2008). Naumann (2009) correspondence between wavenumber ranges and molecular vibrations of specific chemical bonds was used: i) $3700-2996 \mathrm{~cm}^{-1}$ for $\mathrm{O}-\mathrm{H}$ bond vibrations from carboxyl, hydroxyl or phenol groups, and from amides $\mathrm{N}-\mathrm{H}$ vibrations; ii) $2996-2800 \mathrm{~cm}^{-1}$ for lipids with functional groups, $\mathrm{CH}$; iii) $1800-1485 \mathrm{~cm}^{-1}$ for proteins with functional groups, amides I and II; iv) $1485-1185 \mathrm{~cm}^{-1}$ for proteins and lipids with functional groups, $\mathrm{CH}_{2}$ and $\mathrm{CH}_{3}$ as well as phosphate compounds with functional group $\mathrm{P}=0$; and v) $1185-900 \mathrm{~cm}^{-1}$ for polysaccharides with functional groups $\mathrm{C}-\mathrm{O}-\mathrm{C}$ and $\mathrm{C}-\mathrm{O}-\mathrm{P}$.

Therefore, the infra-red (IR) spectra of lyophilized mycelia were recorded between 4000 and $400 \mathrm{~cm}^{-1}$ using a Brucker FTIR with $4 \mathrm{~cm}^{-1}$ resolution. Pellets were prepared mixing $5 \mathrm{mg}$ of lyophilized mycelia with $50 \mathrm{mg} \mathrm{KBr}$ (dried at $105^{\circ} \mathrm{C} / 72 \mathrm{~h}$ ) and compressing the mixture under vacuum.

\subsection{Data analysis}

Nominal (size given by the manufacturer) and secondary sizes of NP (when in aqueous suspensions) were compared by using a one tailed t-test. Repeated measures ANOVAs followed by Dunnett's multiple comparison test were carried out (STATISTICA 6.0 Software ${ }^{\mathrm{TM}}$ ). As significant interactions between concentrations and time were observed, the mean square errors of repeated measures ANOVA were used to compute the standard error of the differences between groups (treatments and control) in the Dunnett's test aiming to correct for simple main effects. The effective concentrations provoking 20 (toxic effects threshold) and $50 \%$ of growth inhibition ( $\mathrm{EC}_{20}$ and $\mathrm{EC}_{50}$, respectively) were computed for the mycelia diameter measured at the end of the assay by using a logistic model.

\section{Results}

\subsection{Characterization of NP in suspension}

Average conductivity values of NP-suspensions ranged from 0.06 $(\mathrm{Fe} / \mathrm{Co})$ to $0.830 \mathrm{mS} / \mathrm{cm}(\mathrm{Mo} / \mathrm{NaO})$ and the average hydrodynamic diameter (Z-average diameter) ranged from $11.3 \mathrm{~nm}(\mathrm{NP}-\mathrm{Au})$ to $718 \mathrm{~nm}$ (Fe/Co), being higher than nominal size (for NP-Au this was only valid for the axial size, being the length size smaller than measured $\mathrm{Z}$-average) (Table $2 ; \mathrm{t}_{2} \geq 2.92, \mathrm{p} \leq 0.05$ ). These results suggest occurrence of NP aggregation after being suspended in Milli-Q ${ }^{\circledR}$ water. This was corroborated by TEM-images (Fig. 1), where aggregates of $\mathrm{Fe} / \mathrm{Co}(\sim 200 \mathrm{~nm})$ and $\mathrm{QD}(\sim 500 \mathrm{~nm})$ were observed, by relatively high values of PDI (0.36 to 0.63 ) and aggregation index (0.199 to 3.92), and by the low zeta potential $(<30 \mathrm{mV}$; as a higher instability is associated with a higher particle aggregation). Suspensions of Fe/Co and SDS/ DDAB were within the category of incipient instability (10 to $30 \mathrm{mV}$ ), those of NP-Au and QD were within the category of moderate stability (30 to $40 \mathrm{mV}$ ), and of Mo/NaO was within the category of excellent stability $(>60 \mathrm{mV})$. All NP exhibited a negative surface charge, except for $\mathrm{NP}-\mathrm{Au}$ that presented a positive surface charge (Table 1 ).

\subsection{Effects of NP-suspensions in mycelial growth}

The mycelium of $L$. sajor caju, P. ostreatus, and T. versicolor required, on average, 8 days to cover the all surface of agar in control Petri dishes, while mycelium of $P$. chrysosporium required 3 days (Fig. 2).

Except for $\mathrm{Fe} / \mathrm{Co}$, exposure to NP provoked a significant growth inhibition of the mycelium of the four fungi species (Fig. 2; $F_{5,11} \geq 24.2$, $\left.\mathrm{p} \leq 10^{-4}\right)$. The QD started to inhibit growth of $L$. sajor caju at day 3 for concentration $4.0 \mathrm{mg} / \mathrm{L}$ and day 5 for 1.0 and $8.0 \mathrm{mg} / \mathrm{L}(\mathrm{q} \geq 2.73$, $\mathrm{p} \leq 0.05$ ). Growth of $P$. chrysosporium was inhibited at 1.0 and $4.0 \mathrm{mg} / \mathrm{L}$ since day 1 , and of $T$. versicolor at 4.0 and $8.0 \mathrm{mg} / \mathrm{L}$ since day
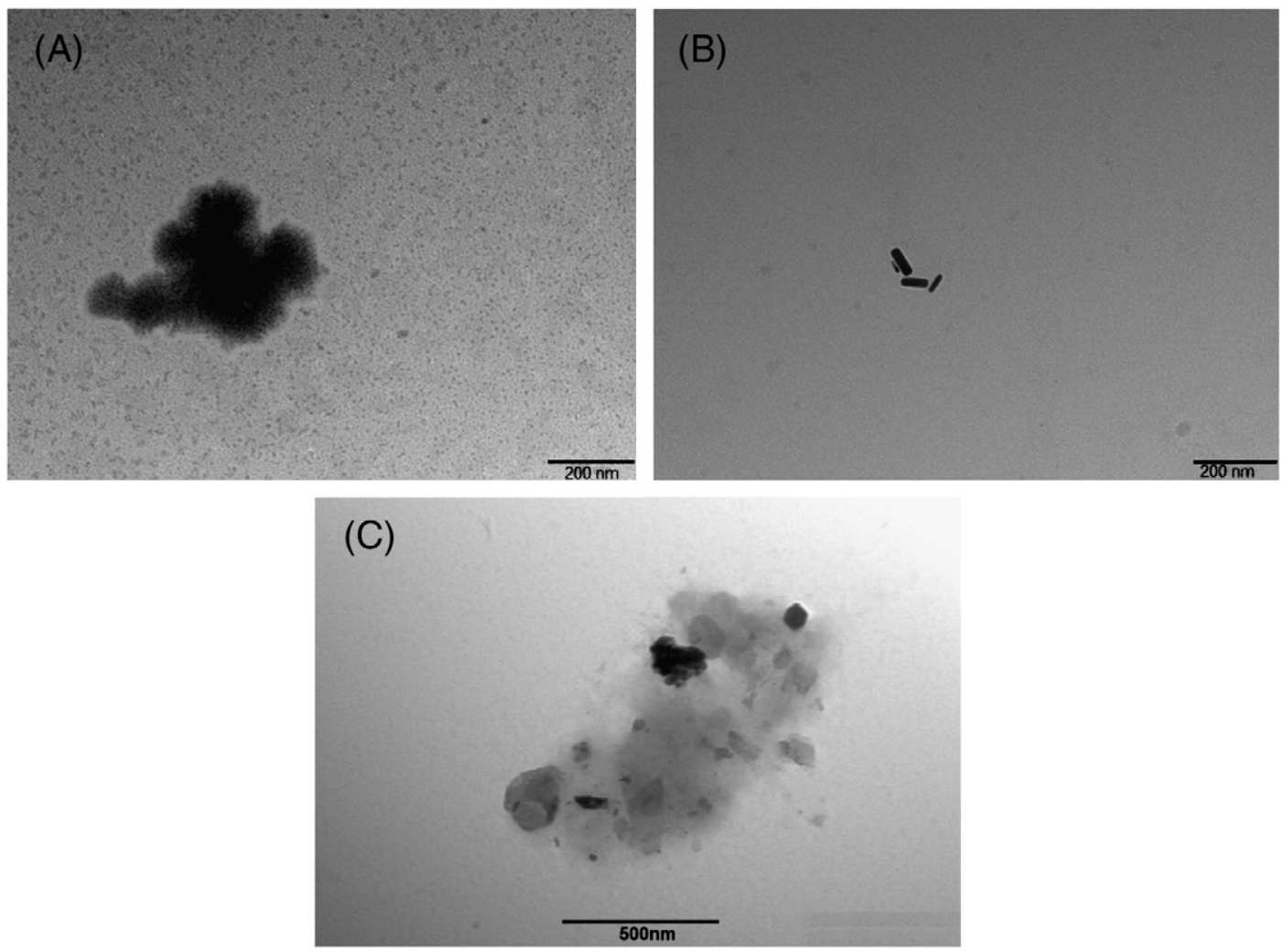

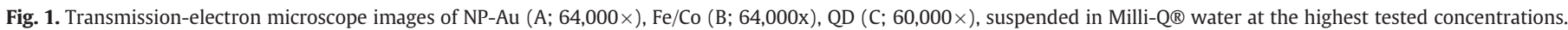


Table 1

Characterization of the highest tested concentrations of nanoparticles, through dynamic light scattering and electrophoretical light scattering

\begin{tabular}{|c|c|c|c|c|c|c|}
\hline & $\begin{array}{l}\text { Nominal size } \\
(\mathrm{nm})\end{array}$ & $\begin{array}{l}\text { Zeta potential } \\
(\mathrm{mV})\end{array}$ & $\begin{array}{l}\text { Conductivity } \\
(\mathrm{mS} / \mathrm{cm})\end{array}$ & $\begin{array}{l}\text { Z-average } \\
(\mathrm{nm})\end{array}$ & $\mathrm{PDI}^{\mathrm{a}}$ & Agregation index \\
\hline $\mathrm{Fe} / \mathrm{Co}$ & 7.0 & $-11.1(9.31)$ & $0.006(0.007)$ & $718(188)$ & $0.630(0.075)$ & $0.260(0.260)$ \\
\hline NP-Au & 10 (axial) 35 (length) & $44.6(3)$ & $0.299(0.003)$ & $11.3(0.07)$ & $0.390(0.002)$ & $-0.670(0.130)$ \\
\hline QD & 3.4 & $-31.1(2.90)$ & $0.009(0.011)$ & $491(15.3)$ & $0.360(0.038)$ & $0.199(0.110)$ \\
\hline SDS/DDAB & 30 & $-9.58(1.40)$ & $0.097(0.007)$ & $193(4.80)$ & $0.458(0.043)$ & $1.52(0.290)$ \\
\hline $\mathrm{Mo} / \mathrm{NaO}$ & 60 & $-105(2.00)$ & $0.009(0.011)$ & $159(29.5)$ & $0.442(0.200)$ & $3.29(1.46)$ \\
\hline
\end{tabular}

Standard deviation in brackets.

a PDI - Polydispersity index.

3 ( $q \geq 2.54, p \leq 0.05)$. Growth inhibition of P. ostreatus occurred at the highest concentration from day 2 until the end of the assay $(q \geq 2.67$, $\mathrm{p} \leq 0.05)$, and by 0.5 and $4.0 \mathrm{mg} / \mathrm{L}$ from day 5 forward $(\mathrm{q} \geq 2.67$, $\mathrm{p} \leq 0.05)$. Regarding NP-Au, growth inhibition of $L$. sajor caju was induced since day 5 at concentrations $15.9,19.1,27.8$, and $33.0 \mathrm{mg} / \mathrm{L}$ ( $q \geq 2.72, p \leq 0.05$ ). All NP-Au concentrations reduced growth of $P$. ostreatus from day 2 until the end of assay ( $\mathrm{q} \geq 2.53, \mathrm{p} \leq 0.05)$. For $P$. chrysosporium only the highest tested concentration decreased its growth and only at day $2(\mathrm{q}=3.74, \mathrm{p} \leq 0.05)$. For $T$. versicolor this same concentration significantly reduced growth from day 2 until the end of assay (Fig. 2; $\mathrm{q} \geq 2.55, \mathrm{p} \leq 0.05$ ). All $\mathrm{Mo} / \mathrm{NaO}$ concentrations decreased the growth of $L$. sajor caju and of $P$. ostreatus from day 3 until the end of assay ( $\mathrm{q} \geq 2.51, \mathrm{p} \leq 0.05$ ). For $P$. chrysosporium only the two highest concentrations inhibited growth (at days 2 and 3), while for
T. versicolor a decrease in growth was observed at days 4 and 5 , at concentrations 9.8, 13.9, and $20.0 \mathrm{~g} / \mathrm{L}$ (Fig. 2 ; $\mathrm{q} \geq 2.63, \mathrm{p} \leq 0.05$ ).

All SDS/DDAB concentrations reduced growth of the four fungi species. For $L$. sajor caju, P. chrysosporium, and T. versicolor these effects started to be observed at day 2 , while for $P$. ostreatus significant effects only started to be observed at day 3 (Fig. 2 ; $\mathrm{q} \geq 2.86$, $\mathrm{p} \leq 0.05$ ).

At the end of assays, the effective concentrations provoking 20 and $50 \%$ ( $\mathrm{EC}_{20}$ and $\mathrm{EC}_{50}$, respectively) of growth inhibition were computed for each NP and each fungus. Regarding NP-Au, these parameters could only be computed for $T$. versicolor (Table 2). However, $\mathrm{EC}_{20}$ and $\mathrm{EC}_{50}$ for $P$. ostreatus and $L$. sajor caju are expected to be lower than those for T. versicolor, since at the lowest concentrations growth inhibitions of $57 \%$ and $45 \%$ were observed for these species, respectively. Values of $\mathrm{EC}_{20}$ and $\mathrm{EC}_{50}$ computed for $\mathrm{QD}$ ranged from 0.759 to $5.16 \mathrm{mg} / \mathrm{L}$ and
(A)
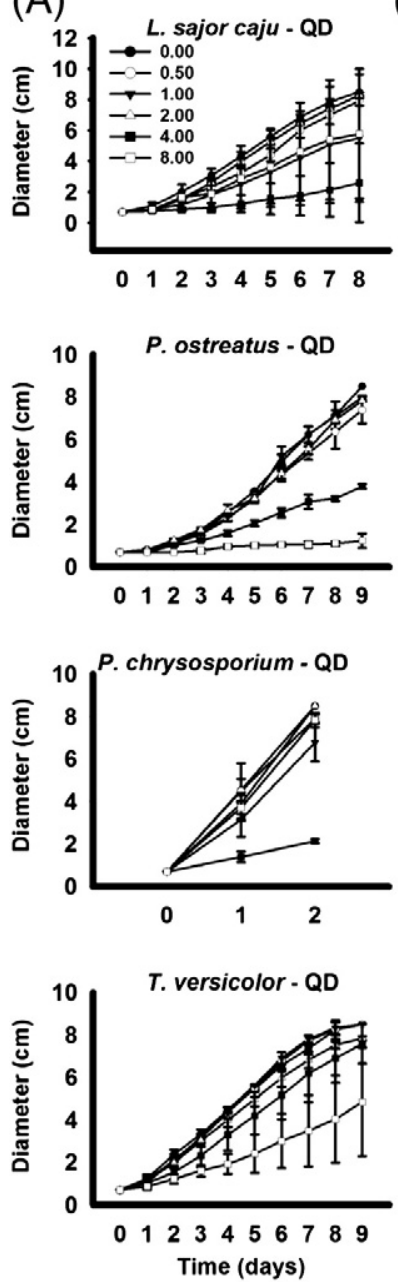

(B)
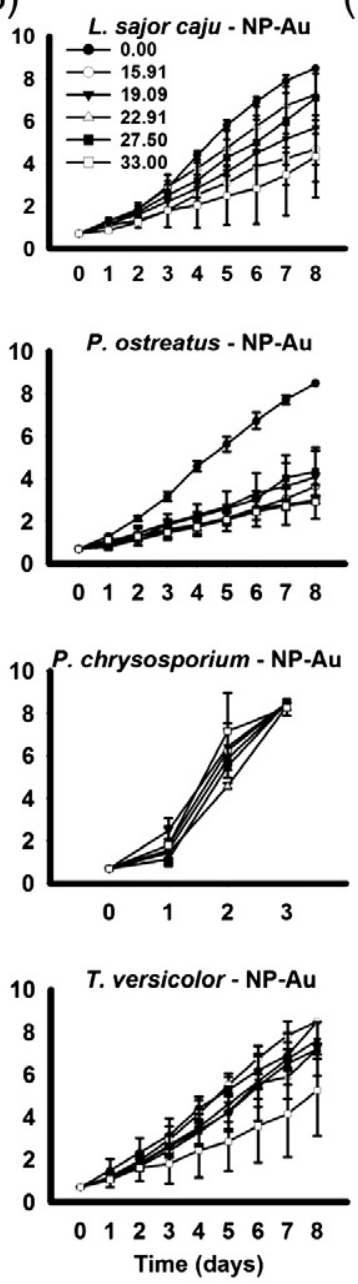

(C)
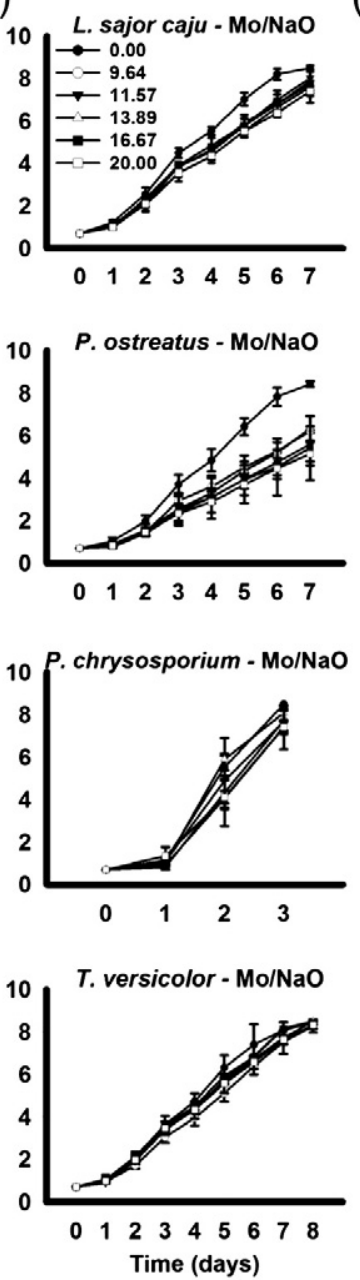

(D)
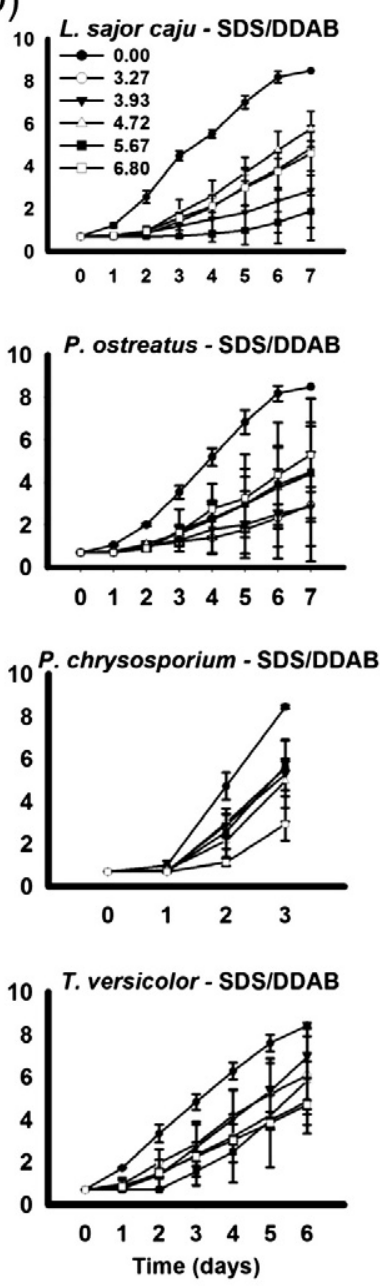

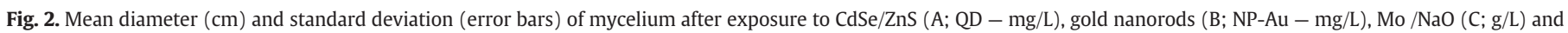
SDS/DDAB (D; g/L) 
from 2.04 to $9.10 \mathrm{mg} / \mathrm{L}$, respectively (Table 2). Lowest values were observed for $L$. sajor caju and the highest for T. versicolor. Regarding $\mathrm{Mo} / \mathrm{NaO}$, it provoked a growth inhibition higher than $20 \%$ only in P. ostreatus, being computed, for this species, an $\mathrm{EC}_{20}$ and $\mathrm{EC}_{50}$ of 7.8 and $33.4 \mathrm{~g} / \mathrm{L}$, respectively. Finally, SDS/DDAB caused a growth inhibition higher than $20 \%$ for all fungi. For $L$. sajor caju and P. ostreatus, the lowest observed growth inhibition was 43 and 66\%, respectively. The $\mathrm{EC}_{20}$ and $\mathrm{EC}_{50}$ for $P$. chrysosporium and $T$. versicolor were similar: 2.4 and $5.1 \mathrm{~g} / \mathrm{L}$, and 3.9 and $7.1 \mathrm{mg} / \mathrm{L}$, respectively.

\subsection{Effects of NP-suspensions in mycelial composition}

Independently of the NP, IR of mycelia from the four fungi exhibited the same pattern in comparison with non-exposed mycelia (control) indicating that no remarkable qualitative changes in fungus biomass composition occurred due to the exposure to each NP. Only slight variations were observed in the absorption band intensities in IR-spectrum of the four fungi exposed to $\mathrm{Fe} / \mathrm{Co}$, in comparison to non-exposed mycelia (data not shown), indicating no substantial quantitative changes in mycelia composition. For the other NP, in general, changes due to NP-exposure only affected absorption band intensities but their pattern of variation was different among species, NP and its concentration. QD caused a general increase of bands intensities comparatively to the control, at lower concentrations, with a decreased tendency as NP concentration increased. Fig. 3 shows an example of this response pattern for P. ostreatus, with variations in the majority of compounds especially those corresponding to carboxyl, hydroxyl, phenol or amides with $\mathrm{O}-\mathrm{H}$ and $\mathrm{N}-\mathrm{H}$ functional groups $\left(3700-2996 \mathrm{~cm}^{-1}\right)$, lipids (2996$\left.2800 \mathrm{~cm}^{-1}, 1485-1185 \mathrm{~cm}^{-1}\right)$, proteins (1800-1485 $\mathrm{cm}^{-1}, 1485-$ $\left.1185 \mathrm{~cm}^{-1}\right)$, and polysaccharides with $\mathrm{C}-\mathrm{O}-\mathrm{C}$ and $\mathrm{C}-\mathrm{O}-\mathrm{P}$ functional groups (1185-900 $\left.\mathrm{cm}^{-1}\right)$.

Concerning NP-Au, minor changes were observed in band intensities, which decreased relatively to control as NP concentration increased, for $P$. ostreatus, $P$. chrysosporium and T. versicolor. L. sajor caju IR-spectra presented similar tendencies as those observed when exposed to QD. For P. chrysosporium exposed to NP-Au main variations in bands absorption were observed for those corresponding to carboxyl, hydroxyl, phenol or amides with $\mathrm{O}-\mathrm{H}$ and $\mathrm{N}-\mathrm{H}$ functional groups, lipids, proteins and polysaccharides. Regarding $\mathrm{Mo} / \mathrm{NaO}$ a general slight increase of all bands intensity was observed in P. ostreatus and $T$. versicolor, with a decrease tendency as NP increased. However, for L. sajor caju and $P$. chrysosporium slight general decrease in band intensities was observed, followed by a slight increase with increasing concentrations of $\mathrm{Mo} / \mathrm{NaO}$. This reflected variations in the carboxyl, hydroxyl, phenol or amides with $\mathrm{O}-\mathrm{H}$ and $\mathrm{N}-\mathrm{H}$ functional groups, lipids, proteins and polysaccharides; smaller changes being observed in mycelia exposed to the highest concentrations (Fig. $3 \mathrm{~b}$ ).

Finally, for SDS/DDAB, in general band intensities decreased as its concentrations increased, especially from 3.3 to $4.7 \mathrm{mg} / \mathrm{L}$ for $T$. versicolor; the main variations corresponded to proteins with functional groups, amides I and II (1800-1485 $\left.\mathrm{cm}^{-1}\right)$ and to polysaccharides with functional groups, $\mathrm{C}-\mathrm{O}-\mathrm{C}$ and $\mathrm{C}-\mathrm{O}-\mathrm{P}$.

\section{Discussion}

In agreement with previous works, the tested NP tended to aggregate when suspended in Milli-Q® water (e.g. Lopes et al., 2012; Pereira et al., 2011). This was expected since it is known that Brownian motion increases as particle size decreases, thus NP exhibit a high probability to collide; jointly with the fact that NP have a high surface area for interactions and that van der Walls attractive force also works for NP, these collisions have a high probability to promote aggregation (Iijima and Kamiya, 2009). It has been reported in literature that larger NP exert lower toxicity than smaller ones (Bar-Ilan et al., 2009). Here, despite the high NP aggregation (larger sizes); QD, NP-Au, Mo/NaO, and SDS/DDAB significantly inhibited the growth of the four fungi and induced changes in the IR-spectrum band intensities. These effects were not size dependent, i.e. could not be associated with the NP-hydrodynamic size, suggesting that most probably the NP chemical composition exerted a higher influence on its ecotoxicity. Bar-llan et al. (2009), after observing that similar sizes of silver and gold-NP exerted significantly different toxicity profiles, proposed that NP chemistry is as important, if not more, as size at inducing adverse effects in vivo. Nevertheless, it would be expected that the large size of NP aggregates would make difficult their transport through the pores of cell wall, suggesting that observed toxicity would be mainly due to the dissociating elements from the NP. It is known that during reproduction the cell wall permeability may change, newly synthesized cell wall being more permeable to NP (Navarro et al., 2008). In addition, cells may interact with NP, which may cause the formation of new bigger pores, thus increasing the possibility of NP internalization through the cell wall (Navarro et al., 2008). This has been related with the fact that higher NP concentrations would promote a higher particle aggregation, and therefore, reduce toxic effects compared to lower concentrations. In the present study, and as mentioned earlier, a relationship between concentration and particles size was not observed, and, thus, this could explain the lack of a concentration-effect relationship (both for growth inhibition and IR-spectra).

Among tested NP, QD exerted the highest toxicity: a concentration as low as $0.759 \mathrm{mg} / \mathrm{L}$ induced a significant growth inhibition and caused changes in the composition of the mycelia. Pereira et al. (2011) and

Table 2

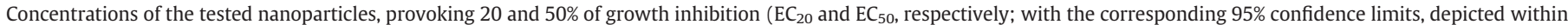
brackets) in the four fungi species, computed at the end of the assay.

\begin{tabular}{|c|c|c|c|c|}
\hline Nanoparticles & Fungi & $\begin{array}{l}\mathrm{EC}_{20} \\
(\mathrm{mg} / \mathrm{L})\end{array}$ & $\begin{array}{l}\mathrm{EC}_{50} \\
(\mathrm{mg} / \mathrm{L})\end{array}$ & $\mathrm{EC}_{50} / \mathrm{EC}_{20}$ \\
\hline \multirow[t]{4}{*}{ NP-Au (mg/L) } & L. sajor caju & n.c. & n.c. & n.c. \\
\hline & P. ostreatus & n.c. & n.c. & n.c. \\
\hline & P. chrysosporium & Highest observed growth inhibition: $3 \%$ & n.c. & \\
\hline & T. versicolor & $27.1(20.5-33.7)$ & $38.0(29.3-46.7)$ & 1.40 \\
\hline \multirow[t]{4}{*}{$\mathrm{QD}(\mathrm{mg} / \mathrm{L})$} & L. sajor caju & $0.759(0.573-0.938)$ & $2.04(1.69-2.57)$ & 2.69 \\
\hline & P. ostreatus & $2.71(2.21-3.21)$ & $4.19(3.76-4.63)$ & 1.55 \\
\hline & P. chrysosporium & 1.38 (n.c.) & 3.36 (n.c.) & 2.44 \\
\hline & T. versicolor & $5.16(2.83-7.49)$ & $9.10(6.32-11.89)$ & 1.76 \\
\hline \multirow[t]{4}{*}{$\mathrm{Mo} / \mathrm{NaO}(\mathrm{g} / \mathrm{L})$} & L. sajor caju & Highest observed growth inhibition: $13 \%$ & n.c. & \\
\hline & P. ostreatus & $7.78(2.74-10.9)$ & $33.5(22.2-23.3)$ & 4.29 \\
\hline & P. chrysosporium & Highest observed growth inhibition: $13 \%$ & n.c. & \\
\hline & T. versicolor & Highest observed growth inhibition: $2 \%$ & n.c. & \\
\hline \multirow[t]{4}{*}{ SDS/DDAB $(\mathrm{g} / \mathrm{L})$} & L. sajor caju & 96.3 (n.c.) & 3497 (n.c.) & n.c \\
\hline & P. ostreatus & n.c & n.c. & n.c. \\
\hline & P. chrysosporium & $2.40(1.46-2.96)$ & $5.13(4.58-6.07)$ & 2.80 \\
\hline & T. versicolor & $3.89(2.87-4.39)$ & $7.09(6.27-9.45)$ & 2.46 \\
\hline
\end{tabular}

n.c. - means that the value could not be computed. 
a) P. ostreatus - Mo/NaO

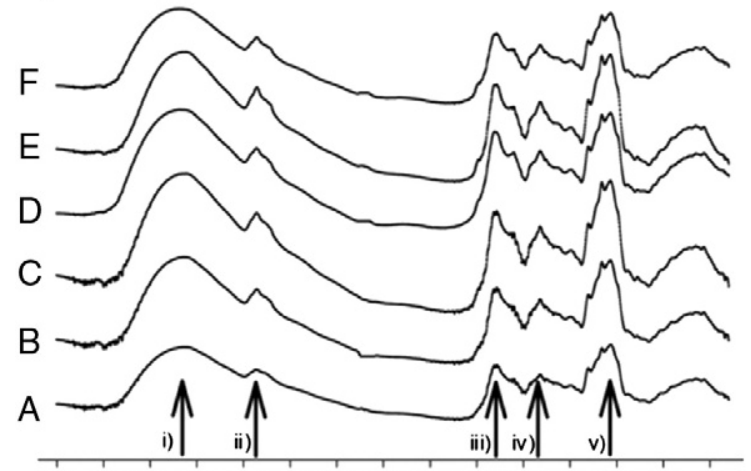

4000375035003250300027502500225020001750150012501000750500 Wave number $\left(\mathrm{cm}^{-1}\right)$

b) P. chryso sporium - Mo/NaO

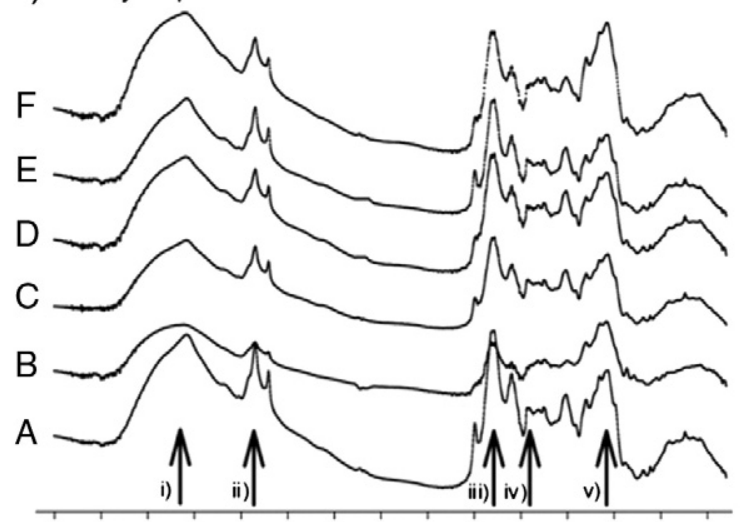

4000375035003250300027502500225020001750150012501000750500 Wave number $\left(\mathrm{cm}^{-1}\right)$
C) P. ostreatus - QD

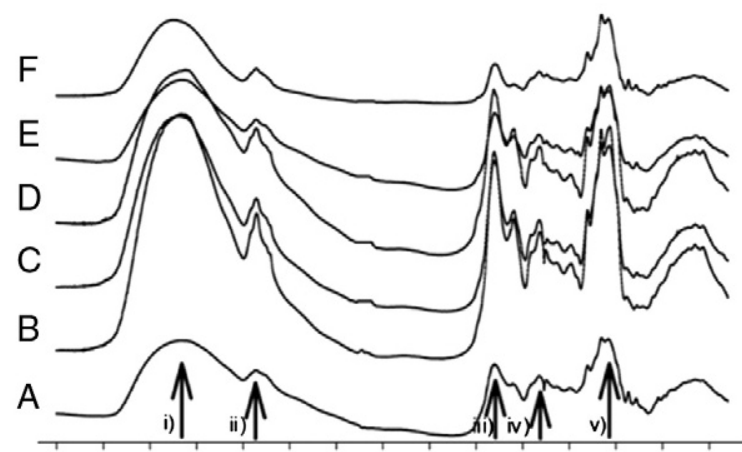

4000375035003250300027502500225020001750150012501000750500 Wave number $\left(\mathrm{cm}^{-1}\right)$

d) P. chrysosporium - NP-Au

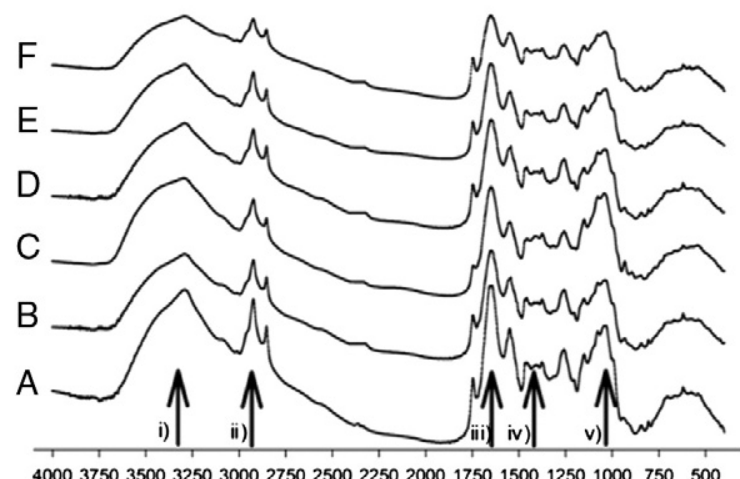

Wave number $\left(\mathrm{cm}^{-1}\right)$

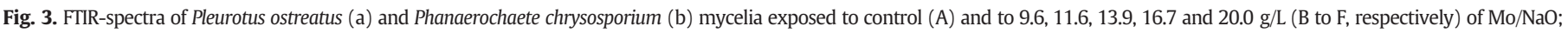

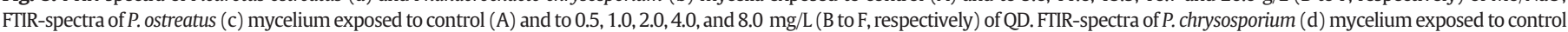

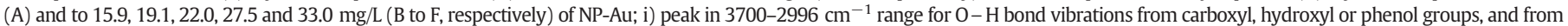

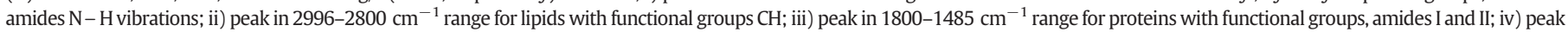

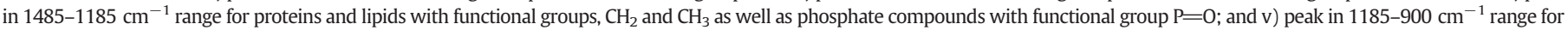
polysaccharides with functional groups $\mathrm{C}-\mathrm{O}-\mathrm{C}$ and $\mathrm{C}-\mathrm{O}-\mathrm{P}$.

Lopes et al. (2012) also observed a high toxicity of QD to the bacteria Vibrio fisheri at low concentrations (EC20 of $0.007 \mathrm{mg} / \mathrm{L}$ ). Furthermore, other researchers also reported a high toxicity of QD on a wide range of species, inducing effects like, for example, damage to the plasma membrane and mitochondrion, DNA fragmentation, leading to cell death (Hardman, 2006). The highest concentrations of QD were associated with a growth inhibition of the mycelia and with a decrease in IR-spectra bands intensity, while the lowest concentrations were associated with a smaller growth inhibition and an increase in the bands of carboxyl, hydroxyl, phenol or amides with $\mathrm{O}-\mathrm{H}$ and $\mathrm{N}-\mathrm{H}$ functional groups, lipids, proteins, and polysaccharides. It is known that, during hypha growth metabolic reactions occur being produced compounds to enable extending tips and hyphae branching, namely polysaccharides (Szeghalmi et al., 2007). Therefore, the lower bands intensity at the highest concentrations may be related to the fact that the fungi are not producing new hyphae and/or to the toxic action of the NP that may lead to the lysis of cells, with concomitant decrease in protein, lipid and polysaccharide contents (Baldrian, 2003). Dhawale et al. (1996) observed that $50 \mathrm{ppm}$ of mercury inhibited P. chrysosporium growth, provoking a concomitant decrease in protein content. The observed increase in bands intensity, even with a significant decrease in growth, could suggest that the fungi, at lower concentrations of QD NP its elements ( $\mathrm{Cd}, \mathrm{Zn}, \mathrm{Se}, \mathrm{S}$ ), are investing in the activation of detoxification/resistance mechanisms to cope with NP exposure. These mechanisms are commonly based on the immobilization of chemicals using extra- and intracellular chelating compounds. It has been shown that fungi exposed to metal contamination produce proteins (metallothioneins) and other phenolic molecules (melanins) to chelate metals (Baldrian, 2003). Furthermore, extracellular hyphal sheath (mainly composed of polysaccharides) may also contribute to the immobilization of metals, decreasing its uptake by the fungi (Baldrian, 2003). Since $\mathrm{QD}$ are composed of $\mathrm{Cd}$ and $\mathrm{Zn}$, it could be expected the fungi to activate this type of defense mechanisms, explaining at least in part, the higher intensity of bands corresponding to proteins and polysaccharides. The NP-Au also induced high toxicity to the four fungi, with concentrations of $27 \mathrm{mg} / \mathrm{L}$ causing a significant growth inhibition of mycelium. However, excepting for $L$. sajor caju, the pattern of changes observed in IR-spectrum were different from those observed for QD. Here the bands intensities were slightly lower than those observed in control, but these differences decreased as NP concentration increased. Therefore, the lower bands intensity within wave numbers corresponding to lipids, proteins and polysaccharides could suggest that fungi are most probably not producing new hyphae and/or the lysis of cells are occurring due to the toxic action of the NP, both being consistent with growth inhibition at the highest concentrations. However, as for QD, L. sajor caju seems to be able to activate defense mechanisms at lower concentrations of NP-Au, as an increase in the bands intensity was observed at such concentrations. Lopes et al. (2012) and Pereira et al. (2011) have also reported the toxicity of NP-Au for $V$. fisheri. These NP were shown to induce upregulation of antioxidants, stress response genes and protein expression for human fetal 
lung cells (Li et al., 2010), and oxidative stress in Mytilus edulis (Tedesco et al., 2010).

Regarding organic NP, fungi exhibited a higher resistance to $\mathrm{Mo} / \mathrm{NaO}$ and to SDS/DDAB comparatively to QD and NP-Au, which was expected since these organisms are known to be able to degrade organic compounds (Ryu et al., 2000). In the present study, different responses of the fungi to these two NP were observed when analyzing the IR-spectra. For $\mathrm{Mo} / \mathrm{NaO}$ this pattern varied with concentrations and fungi, reflecting the variation in growth inhibition along the tested concentration. For example, for P. chrysosporium, L. sajor caju and T. versicolor the lowest concentrations of $\mathrm{Mo} / \mathrm{NaO}$ started first to inhibit growth. In the case of $P$. chrysosporium and L. sajor caju this may explain the registered lower intensity in bands. For $P$. ostreatus, all concentrations started to inhibit growth at day 3 , which was accompanied by an increase in bands intensity followed by a decrease, suggesting again the activation of defense mechanisms at lower concentrations. Regarding SDS/DDAB, all tested concentrations significantly inhibited growth of the four fungi since day 3 or 4 , being accompanied by a decrease in the bands intensity. Thus, suggesting that the fungi were most probably not producing new hyphae and/or the lysis of cells was occurring due to the toxic effects of the vesicles or of its components (SDS; DDAB).

In general, the four fungi exhibited different sensitivities to the tested $\mathrm{NP}$ and as well different responses. P. ostreatus was the most sensitive species to $\mathrm{Mo} / \mathrm{NaO}$; comparatively, the other three species were quite tolerant to this NP, as all exhibited a growth inhibition $\leq 13 \%$. Conversely, $P$. chrysosporium and $T$. versicolor were the least sensitive species to $\mathrm{NP}-\mathrm{Au}$ and QD, respectively.

Finally, regarding the toxicity of the tested NP, according to the results for growth inhibition and to the classification of the European Union Commission Guideline 93/67/EEC-Annex 1 (1996), NP-Au should be placed in the category of harmful as at least one tested fungi species exhibited an $\mathrm{EC}_{20}$ (effects threshold) within the range of 10 to $100 \mathrm{mg} / \mathrm{L}$. The QD was the NP exerting the highest effects in growth of fungi, the most sensitive responses $\left(\mathrm{EC}_{20}\right)$ measured for this $\mathrm{NP}$ was $0.759 \mathrm{mg} / \mathrm{L}$ for $L$. sajor caju, thus, within the categories of "very toxic". The toxicity category "not harmful" can be used for NP with an $\mathrm{EC}_{20}$ above $100 \mathrm{mg} / \mathrm{L}$ : $\mathrm{Mo} / \mathrm{NaO}$ (lowest computed $\mathrm{EC}_{20}=7.78 \mathrm{~g} / \mathrm{L}$ ), $\mathrm{SDS} / \mathrm{DDAB}$ (lowest computed $\mathrm{EC}_{20}=2.40 \mathrm{~g} / \mathrm{L}$ ), and $\mathrm{Co} / \mathrm{Fe}$ (which did not significantly inhibit the growth of any tested species of fungi).

\section{Conclusion}

Data gathered here support the fact that NP may adversely affect microorganism, contributing to the increased concern on their release into the environment, in this case specifically into the soil compartment. This is one of the first studies demonstrating NP effects in growth and in mycelium chemical composition of terrestrial fungi. Furthermore, the results here obtained reinforce the need to generate more knowledge on the behavior and ecotoxicity for specific NP, since they suggest that NP may exhibit diversified modes of action and the sensitivity of species.

\section{Acknowledgments}

This work was partially funded by Fundação para a Ciência e a Tecnologia through individual research grants attributed to Toni Galindo (SFRH/BD65922/2009), Dina Rodrigues (SFRH/BD/77647/ 2011), Ana Freitas (SFRH/BPD/73781/2010), Teresa Rocha-Santos (SFRH/BPD/65410/2009) and through FSE and POPH funds (Programa Ciência 2007), and through the bilateral cooperation FCT/CNPq (ARENA project).

\section{Appendix A. Supplementary data}

Supplementary data to this article can be found online at http:// dx.doi.org/10.1016/j.scitotenv.2013.04.019.

\section{References}

Antunes FE, Marques EF, Gomes R, Thuresson K, Lindman B, Miguel MG. Network formation of catanionic vesicles and oppositely charged polyelectrolytes. Effect of polymer charge density and hydrophobic modification. Langmuir 2004;20:4647-56.

Baldrian P. Interactions of heavy metals with white-rot fungi. Enzyme Microb Technol 2003;32:78-91.

Bar-Ilan O, Albrecht RM, Fako VE, Furgeson DY. Toxicity assessments of multisized gold and silver nanoparticles in zebrafish embryos. Small 2009;5:1897-910.

Behrens S, Bönnemann H, Matoussevitch N, Gorschinski A, Dinjus E, Habicht W, et al. Surface engineering of $\mathrm{Co}$ and $\mathrm{FeCo}$ nanoparticles for biomedical application. J Phys Condens Matter 2006;18:S2543-61.

Bernhardt ES, Colman BP, Hochella MF, Cardinale BJ, Nisbet RM, Richardson CJ, et al. An ecological perspective on nanomaterial impacts in the environment. J Environ Qual 2010;39:1-12.

Bing-Ru L, Guo-Mei J, Jian C, Gang W. A review of methods for studying microbial diversity in soils. Pedosphere 2006;16:18-24.

Borné J, Nylander T, Khan A. Vesicle formation and other structures in aqueous dispersions of monoolein and sodium oleate. J Colloid Interface Sci 2003;257:310-20.

Commission of the European Communities. Technical Guidance Document in Support of Commission Directive 93/67/EEC on risk assessment for new notified substances and commission regulation (EC) No 1488/94 on risk assessment for existing substances part II. Environmental risk assessment. Luxembourg: Office for Official Publications of the European Communities; 1996.

Dhawale SS, Lane AC, Dhawale SW. Effects of mercury on the white rot fungus Phanerochaete chrysosporium. Bull Environ Contam Toxicol 1996;56:825-32.

Dinesh R, Anandaraj M, Srinivasan V, Hamza S. Engineered nanoparticles in the soil and their potential implications to microbial activity. Geoderma 2012;173-174:19-27.

Dreaden EC, Alkilany AM, Huang X, Murphy CJ, El-Sayed MA. The golden age: gold nanoparticles for biomedicine. Chem Soc Rev 2012;41:2740-79.

Ferreira DA, Bentley MVLB, Karlsson G, Edwards K. Cryo-TEM investigation of phase behaviour and aggregate structure in dilute dispersions of monoolein and oleic acid Int J Pharm 2006;310:203-12.

Hardman R. A toxicologic review of quantum dots: toxicity depends on physicochemical and environmental factors. Environ Health Perspect 2006;114:165-72.

Heinlaan M, Kahru A, Kasemets K, Arbeille B, Prensier G, Dubourguier H-C. Changes in the Daphnia magna midgut upon ingestion of copper oxide nanoparticles: a transmission electron microscopy study. Water Res 2011;45:179-90.

Iijima M, Kamiya H. Surface modification for improving the stability of nanoparticles in liquid media. KONA 2009;27:119-29.

Kahru A, Dubourguier H-C. From ecotoxicology to nanoecotoxicology. Toxicology 2010;269: 105-19.

Klaine SJ, Alvarez PJJ, Batley GE, Fernandes TF, Handy RD, Lyon DY, et al. Nanomaterials in the environment: behavior, fate, bioavailability, and effects. Environ Toxicol Chem 2008;27:1825-51.

Landsiedel R, Kapp MD, Schulz M, Wiench K, Oesch F. Genotoxicity investigations on nanomaterials: methods, preparation and characterization of test material, potential artifacts and limitations - many questions, some answers. Mutat Res Rev Mutat Res 2009;681:241-58.

Li JJ, Hartono D, Ong C-N, Bay B-H, Yung L-YL. Autophagy and oxidative stress associated with gold nanoparticles. Biomaterials 2010;31:5996-6003.

Lopes I, Ribeiro R, Antunes F, Rocha-Santos T, Rasteiro M, Soares A, et al. Toxicity and genotoxicity of organic and inorganic nanoparticles to the bacteria Vibrio fischeri and Salmonella typhimurium. Ecotoxicology 2012;21:637-48.

Manzo S, Rocco A, Carotenuto R, De Luca Picione F, Miglietta M, Rametta G, et al. Investigation of ZnO nanoparticles' ecotoxicological effects towards different soil organisms. Environ Sci Pollut Res 2011;18:756-63.

Mouchet F, Landois P, Datsyuk V, Puech P, Pinelli E, Flahaut E, et al. International amphibian micronucleus standardized procedure (ISO 21427-1) for in vivo evaluation of double-walled carbon nanotubes toxicity and genotoxicity in water. Environ Toxico 2011;26:136-45.

Movasaghi Z, Rehman S, ur Rehman DI. Fourier transform infrared (FTIR) spectroscopy of biological tissues. Appl Spectrosc Rev 2008;43:134-79.

Naumann A. A novel procedure for strain classification of fungal mycelium by cluster and artificial neural network analysis of Fourier transform infrared (FTIR) spectra. Analyst 2009;134:1215-23.

Navarro E, Baun A, Behra R, Hartmann N, Filser J, Miao A-J, et al. Environmental behavior and ecotoxicity of engineered nanoparticles to algae, plants, and fungi. Ecotoxicology 2008; 17:372-86.

Nogueira V, Lopes I, Rocha-Santos T, Santos AL, Rasteiro GM, Antunes F, et al. Impact of organic and inorganic nanomaterials in the soil microbial community structure. Sci Total Environ 2012;424:344-50.

Ong PL, Mahmood S, Zhang T, Lin JJ, Ramanujan RV, Lee P, et al. Synthesis of FeCo nanoparticles by pulsed laser deposition in a diffusion cloud chamber. Appl Surf Sci 2008;254:1909-14.

Pereira R, Rocha-Santos TAP, Antunes FE, Rasteiro MG, Ribeiro R, Gonçalves F, et al. Screening evaluation of the ecotoxicity and genotoxicity of soils contaminated with organic and inorganic nanoparticles: the role of ageing. J Hazard Mater 2011;194:345-54.

Ryu W, Shim S, Jang M, Jeon Y, Oh K, Cho M. Biodegradation of pentachlorophenol by white rot fungi under ligninolytic and nonligninolytic conditions. Biotechnol Bioproc Eng 2000;5:211-4.

Salvaterra T, Alves MG, Domingues I, Pereira R, Rasteiro MG, Carvalho RA, et al. Biochemical and metabolic effects of a short-term exposure to nanoparticles of titanium silicate in tadpoles of Pelophylax perezi (Seoane). Aquat Toxicol 2012;15:128-129C. [190-192].

Schumacher, Nag A, Waldman WJ, Dutta PK. Direct synthesis of aqueous CdSe/ZnS-based quantum dots using microwave irradiation. J Phys Chem 2009:12132-9. 
Scown TM, van Aerle R, Tyler CR. Review: do engineered nanoparticles pose a significant threat to the aquatic environment? Crit Rev Toxicol 2010;40:653-70.

Szeghalmi A, Kaminskyj S, Gough K. A synchrotron FTIR microspectroscopy investigation of fungal hyphae grown under optimal and stressed conditions. Anal Bioanal Chem 2007;387:1779-89.

Tedesco S, Doyle H, Blasco J, Redmond G, Sheehan D. Oxidative stress and toxicity of gold nanoparticles in Mytilus edulis. Aquat Toxicol 2010;100:178-86.
Tourinho PS, van Gestel CAM, Lofts S, Svendsen C, Soares AMVM, Loureiro S. Metal-based nanoparticles in soil: fate, behavior, and effects on soil invertebrates. Environ Toxicol Chem 2012;31:1679-92.

Wiesner MR, Lowry GV, Alvarez P, Dionysiou D, Biswas P. Assessing the risks of manufactured nanomaterials. Environ Sci Technol 2006;40:4336-45. 